\title{
The use of trenchless technology in the expansion of the natural gas network in the city of São Paulo, Brazil
}

\begin{abstract}
With the increase in the production of natural gas from the pre-salt discoveries, the use of this energy source gained momentum in the everyday uses (residences, commerce, service) as channelized infrastructure of distribution, Aiming at greater ease in the use of the network service compared to the cylinders. However, considering that the infrastructure for natural gas reaches the Brazilian cities in general when they are already formed and densely occupied, the use of a method that generates the least possible disturbance in terms of time of the work, is a key element in the dynamics of large cities. This is the concept of sustainability that includes non-destructive technology (trenchless technology). This method opens minimum holes in the paving and through these holes, inserts the duct with minimal interdiction of the road, movement of land and annoyance to the surrounding population. This text provides a quick overview of the use of this method in the city of São Paulo (Brazil).
\end{abstract}

Keywords: trenchless technology, horizontal directional drilling, HDD, natural gas, infrastructure, São Paulo
Volume 3 Issue 4 - 2017

\section{Vanessa Meloni Massara}

Adjunct Researcher, Polytechnic School, University of Sao Paulo, Brazil

Correspondence: Vanessa Meloni Massara, Civil Engineer, Ph.D in Energy Planning, Adjunct Researcher, Polytechnic School, University of Sao Paulo, Brazil, Tel 55 I-|42-244-176, Emailvmmassara@usp.br

Received: April 27, 2017 | Published: November 07, 2017

\section{Introduction}

In Brazil the constant need for heating is not common. This is probably one of the reasons why the underground gas network has made little progress until the early 2000s. São Paulo, the most developed city in the country, began to expand the use of natural gas network through two factors: privatization of the gas company in 1999, moving the business to COMGÁS, a British Petroleum subsidiary, which created a plan for the dissemination of gas infrastructure for residential and commercial uses and also for the pre-salt discoveries in the Santos Basin initiated In 2003 and the Federal program for the natural gas uses expansion. ${ }^{1}$ Figure 1 shows the increased of natural gas consumption. This process of intensification of the underground network continued with the Paulista Petroleum and Natural Gas Program, created by the State Council of Oil and Gas in 2010. ${ }^{2}$
However, the expansion of the network for daily uses found as main difficulty, the execution of pipelines in areas densely occupied, which in the first analysis would lead to difficulties with the interdiction of streets and avenues and the lack of mapping of other subsoil networks (water, sewage), generating problems in the random excavation to insert the new ducts. To minimize the disturbance of this execution, trenchless technology was introduced in Brazil: an easy and fast method of pipeline introduction in consolidated urban areas. "Trenchless technology covers any techniques, processes or procedures, including the equipment, machines and materials involved, which minimizes or eliminates the need for surface excavation or reduces environmental damage or reduces the associated costs for underground work". ${ }^{4}$ The social and environmental impacts of utility works are represented on Figures $1 \& 2 .^{5}$

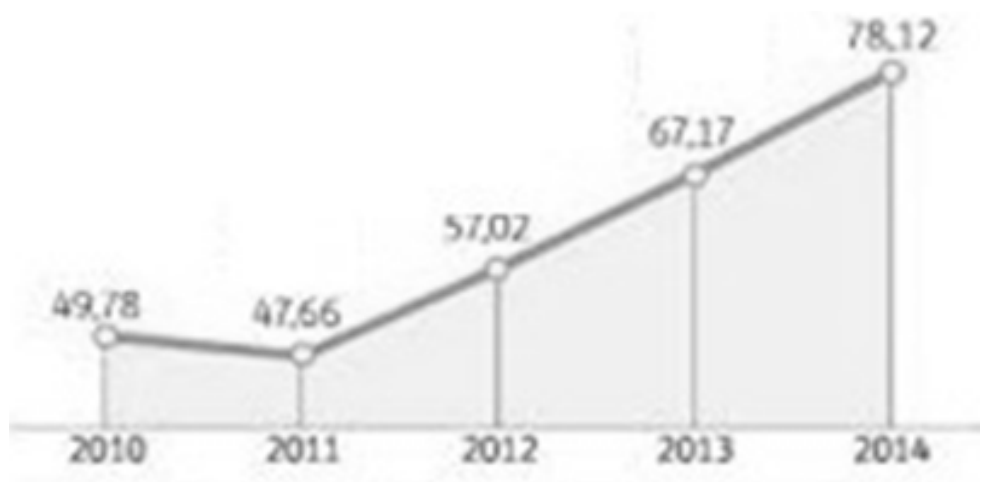

Figure I Consumption of natural gas 2010-2014 (million $\mathrm{m}^{3} /$ day).

Source: ${ }^{2}$ 


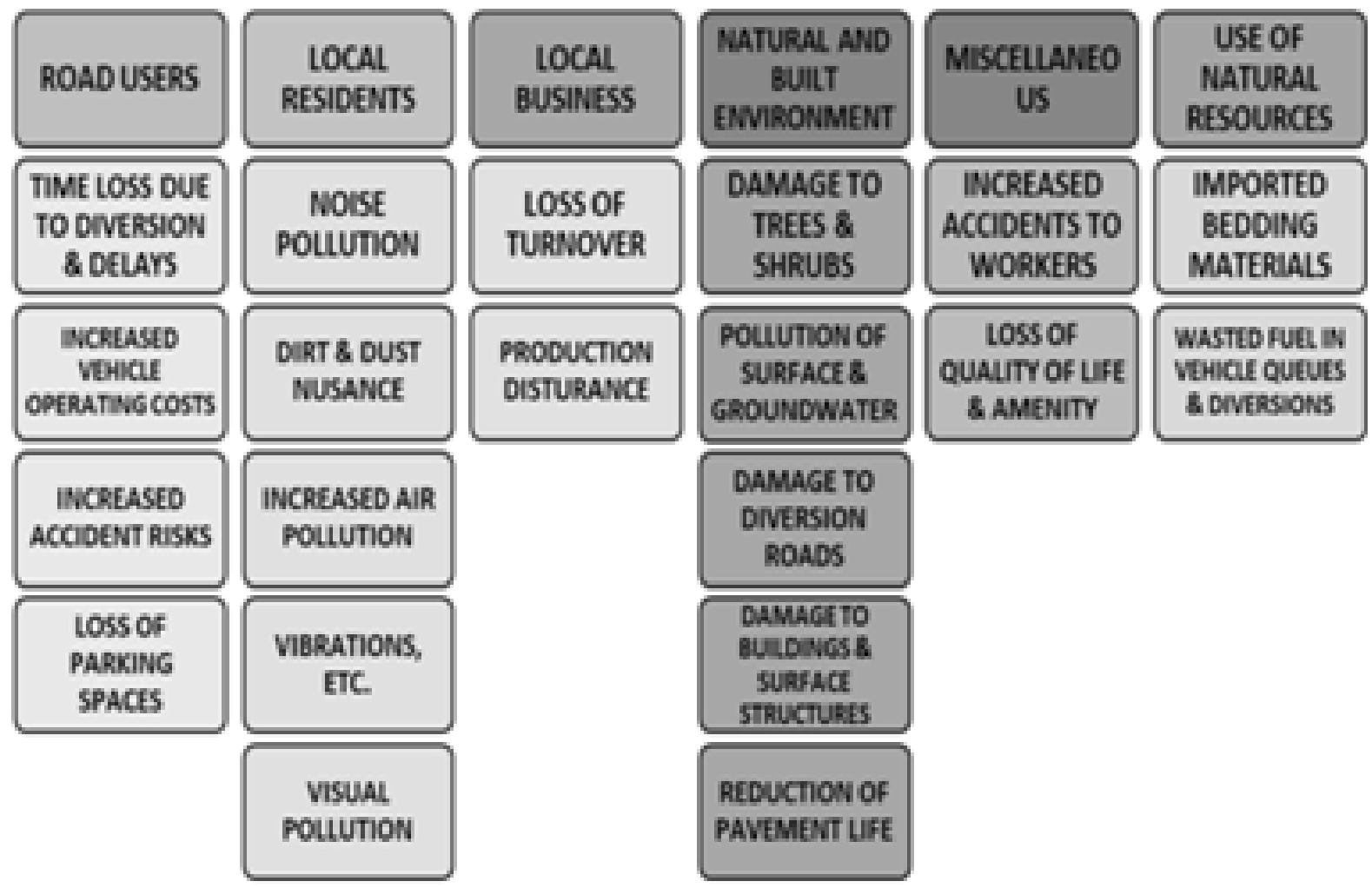

Figure 2 Source: extracted from. ${ }^{5}$

\section{Case presentation}

The most non-destructive method used in Brazil is the horizontal directional drilling (HDD). From the starting pit, a rod is used for horizontal drilling of the ground by rotation using the injection of water or compressed air as lubricant, expelled by diffusers at the stem head. The drilling is directed through a transmitter also at the stem head, ensuring the guideline and determined depths. An appropriate reamer is then placed, allowing the pilot hole to increase the desired diameter. The tubing is secured directly behind the reamer and carefully pulled through the hole. ${ }^{6}$ The ducts used to install natural gas are the high density polyethylene (HDPE). Its use follows the quality assurance program of the Brazilian Association of Polyolefin Tubes and Systems (ABPE) based on ISO 4437, ${ }^{7}$ and the Brazilian standard NBR $14462 .{ }^{8}$ The requirements for holes closure and paving are reduced and it is only necessary to measure the maximum bulging for surface regularity; And at the points of entry and exit of the drilling equipment that resulting in inspection box, the finishing of the plug shall be the same coating as the rolling range, maintaining the leveling of the paving. The direct cost in many cases is already equivalent to the conventional method of trenching. ${ }^{1}$

\section{Discussion}

São Paulo, like other metropolises, has an occupation of its subsoil very congested bordering on the limit of intolerance. Most of the old networks of water, sewage and electricity were not mapped until the early 2000s, making difficult to use the trenchless technology concepts. Since 2003, the guidelines were revised and emphasized the subsurface mapping problematic and thus, infrastructure concessionaires were

required to prepare the digital mapping of networks, favoring the introduction of the natural gas network without damages to the other networks already installed. As a precaution, equipment such as the pipe locator is also used, sweeping the subsoil and indicating the existence of other networks. Considering the dynamics of cities the use of trenchless technology acts as a diffusion agent and optimizer of the natural gas expansion facilitating its sustainable introduction in everyday urban uses.

\section{Acknowledgments}

None.

\section{Conflicts of interest}

There isn't any conflict of interest.

\section{Funding}

None.

\section{References}

1. Massara VM. Urban Dynamics in the natural gas infrastructure optimization (doctoral thesis). Brazil: University of São Paulo. 2007;36-46.

2. National Agency for Oil, Natural Gas and biofuels. Statistical Yearbook 2017. Agência Nacional do Petróleo, Gás Natural e Biocombustíveis, Brazil; 2017.

3. International Society for Trenchless Technology. An Environmentally Sound Approach for Underground Services: An Introductory Guide for Decision-Makers (IETC urban environment series). UNEP, Kenya. 2001. 
4. The International Society for Trenchless Technology. What is Trenchless Technology? 2017.

5. Belani D, Pitroda J, Bhavsar JJ. A review on trenchless technology: state of art technology for underground utility services. In: National Conference on: Trends and Challenges of Civil Engineering in Today's Transforming World, Gujarat, India. 2014;1-14.

6. Najafi M. Trenchless technology: pipeline and utility design, construction, and renewal. $1^{\text {st }}$ edn. McGraw-Hill: USA; 2005.
7. International Organization for Standardization. ISO 4437: Plastics piping systems for the supply of gaseous fuels - Polyethylene. 2014.

8. Brazilian Association of Technical Standards. NBR 14462: PE 80 and PE 100 polyethylene pipes for gas distribution buried. 2000. 